\title{
The Role of Online Social Networks in Human Resources and Career Management
}

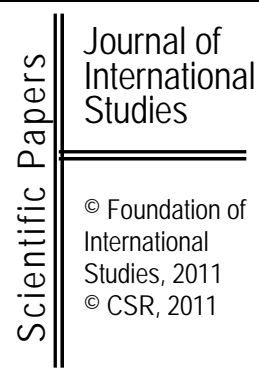

Pawel Korzynski

Visiting Fellow

Harvard Business School

pkoryynski@fas.harvard.edu

\begin{abstract}
In the late 1980s, researchers noticed that some managers were better than other managers at accomplishing goals through social networks (Kotter, 1990). Other economics and management scholars found, that certain patterns of connections, which individuals build with others, enable them better jobs, higher salary, promotions and overall greater career success (Granovetter, 1974; Burt, 1992). During the past few years we have witnessed a transformation of many traditional working environment to a IT enabled 'e-workplace' (Arnison \& Miller, 2002). That is why this paper examines what the role of online social networks is in career management and human resources management. It points out at some behaviours of individuals on social networking platforms and also analyses, how companies use online social networks.
\end{abstract} Submitted: September, 2011 $1^{\text {st }}$ revision: October, 2011 Accepted: November, 2011

Keywords: online social networks, human resources management, career management, job search, Internet.

JEL classification: O15 J64, L86.

\section{Introduction}

Mass communication using the Internet and mobile technology has created new possibilities for the development of social networks. Transferring from the web 1.0 to the web 2.0 communication standard means changing the paradigm of interaction between website administrators and delegating the creation of most content to users who exchange information within various socials networks.

It happens that a single piece of information, published in an online social network and quickly popularised by thousands or even millions of people, may affect one's image and sometimes even bring the risk of business, professional or social marginalisation. There are many available examples of people, companies and organisations which show how easy it may be to ruin reputation which was built for years. Probably, one could find even more examples of people, companies and organisations that stay in the shadow of others because they avoid belonging to online social networks.

The aim of the research project is to understand users' behaviours on the professional social networking platform. Furthermore we are going to study users' goals on the platform. Finally we will analyse how companies can use platforms for better outcomes.

Online social networks enable individuals and companies to connect in the world of work. In future it seems to be necessary to include social networking strategy in career 
management plan and in human resources management strategy.

In order to use social networks effectively, it is important to fully understand the possibilities of network sites and behaviors of networking users.

\section{Review of main theories on social networks}

There are two main different views regarding social networks, which explain the role of social networks. The first view, so called the pipe view, argues that networks are conduits which enable to transfer information concerning goods, resources, opportunities between interested parties (Podolny, 2001).

Research on the role of networks in job searches, falls into this category. So as to explain value of networks as pipes Granovetter (1974) underlined the importance of a position characterized by weak ties, between actors. It turned out that majority of his respondents found jobs through informal connections such as friends or colleagues. That is why he pointed at the importance of weak ties in searching for a better job. He argued that weak ties are important in job mobility because they function as bridges between networks, allowing individuals to connect to others who are not already in their network. Through these connections, individuals are able to find out about jobs that they may not have heard about through formal channels and through their strong ties.

Burt (1992) referring to this theory, argued that stronger ties bring more advantages than weak ties, because they allow a greater volume of resources to transfer between actors. It was confirmed by other research on buyer-supplier relations that emphasizes the relative advantages of long-term more intensive, relations over short-term, weaker market connections (Dore, 1983; Uzzi, 1996).

Furthermore, the view of networks as pipes suggest that actors (companies or individuals), so as to have better outcomes, occupy structural holes or put themselves in positions of power (Pfeffer and Salancik, 1978; Burt, 1992; Casciaro and Piskorski, 2005).

A second view of networks, so called prism view suggests, that a tie between two market actors does not function only as a pipe conveying resources between those two actors. Many market actors, which observe the presence or absence of a tie between two actors, draw conclusions regarding the quality of one or both of the market actors. For example, day care centres can improve their image in the eyes of potential consumers by establishing ties to prominent organizations in the community, such as church groups or governmental agencies (Baum and Oliver, 1992). In a research of investment banks (Podolny, 1993), the syndicate relations between investment banks are important because these syndicate relations enable the basis for a status ordering that corporate issuers and investors use to infer about the quality of the banks.

Furthermore other scholars argued that actors are very exclusive in the patterns of their relationships so as to facilitate their status positions (Jensen, 2003), and are very clear about the identity they are conveying to others (Zuckerman, Kim, Ukanwa, and von Rittmann, 2003; Zuckerman, 2004).

There is also the third view of networks, which can be observed on online social networking platforms. This view presents networks as covers. In this conception, interactions with users give actors an excuse to engage in other behaviours and simultaneously maintaining plausible deniability that they are not engaging in such activities. This can be useful to individuals, who are employed and would not like to be noticed on the market as users looking for another employer (Piskorski, 2008). It is worth mentioning that while the prism view recommends that actors are rather exclusive and very clear about the identity they are conveying, networks as prisms suggests that actors engage in many non-exclusive and ambiguous interactions to make it difficult for anyone to make inferences about them. 


\section{Online social networking platforms and research methodology}

Social networking sites such as Twitter and Facebook are used all over the world so as to promote their products and services. Profiles on these sites are more concentrated on entertainment. However there are also a lot of networking sites that are focused on business and career networking. A good example of such professional networking sites is LinkedIn. LinkedIn was founded in December 2002 and launched in May 2003, is mainly used for professional networking. In 2011, LinkedIn reported more than 100 million registered users, spanning more than 200 countries and territories worldwide (Parr, 2011). There are also regional professional networking sites, which are popular in particular countries like for example Xing in Germany, Viadeo in France, Spain and China or GoldenLine in Poland.

The study's participants were experienced professionals registered on GoldenLine and working in two different sectors: finance and banking as well as medical and pharmaceutical sector. Data were collected through structured surveys delivered through GoldenLine to experienced professionals. A total of 574 matched questionnaires were returned (221 from finance and banking and 353 from medical and pharmaceutical sector). Statistical analysis, using SPSS and STATA software, was conducted to assess the research results.

\section{Users' behaviour on the professional social networking platform}

Some previous research argued that 70\% users' activities on social networking platform is related to the learning about other users' profilers (Silverthorne, 2009). It is very common among users of social networking sites like Facebook. However, following the research on GoldenLine, it is possible to claim that activities undertaken on social networking websites that are related to career and labour market are slightly different because user profiles usually contain only one photograph and a lot of information on professional experience, education and competencies. Graph 1 shows what kind of activities are undertaken by the users of the GoldenLine website assuming that each user was allowed to choose more than one activity. It shows that $42.40 \%$ of the users most often concentrate on searching and reviewing information about business partners whereas $41.35 \%$ learn about professional careers of other users. It is very probable that users pay attention also to contacts of other users which helps them draw conclusions about the roles they play in their organisation or business venture. An additional research in this scope, performed in the future, would make an interesting reference to the networks as prism view.

$41.39 \%$ of the users declare that they join discussion forums and $39.09 \%$ manage information on their own profiles. This information is valuable for companies, which could stimulate group discussions and influence at least some of profiles' data which is managed by users.

$35.69 \%$ of survey respondents, most often those on the GoldenLine.pl website, are engaged in comparing their own career paths, $28.03 \%$ - send messages to their contacts or other users whereas $11.04 \%$ - update information in order to share it with other users of the website. 


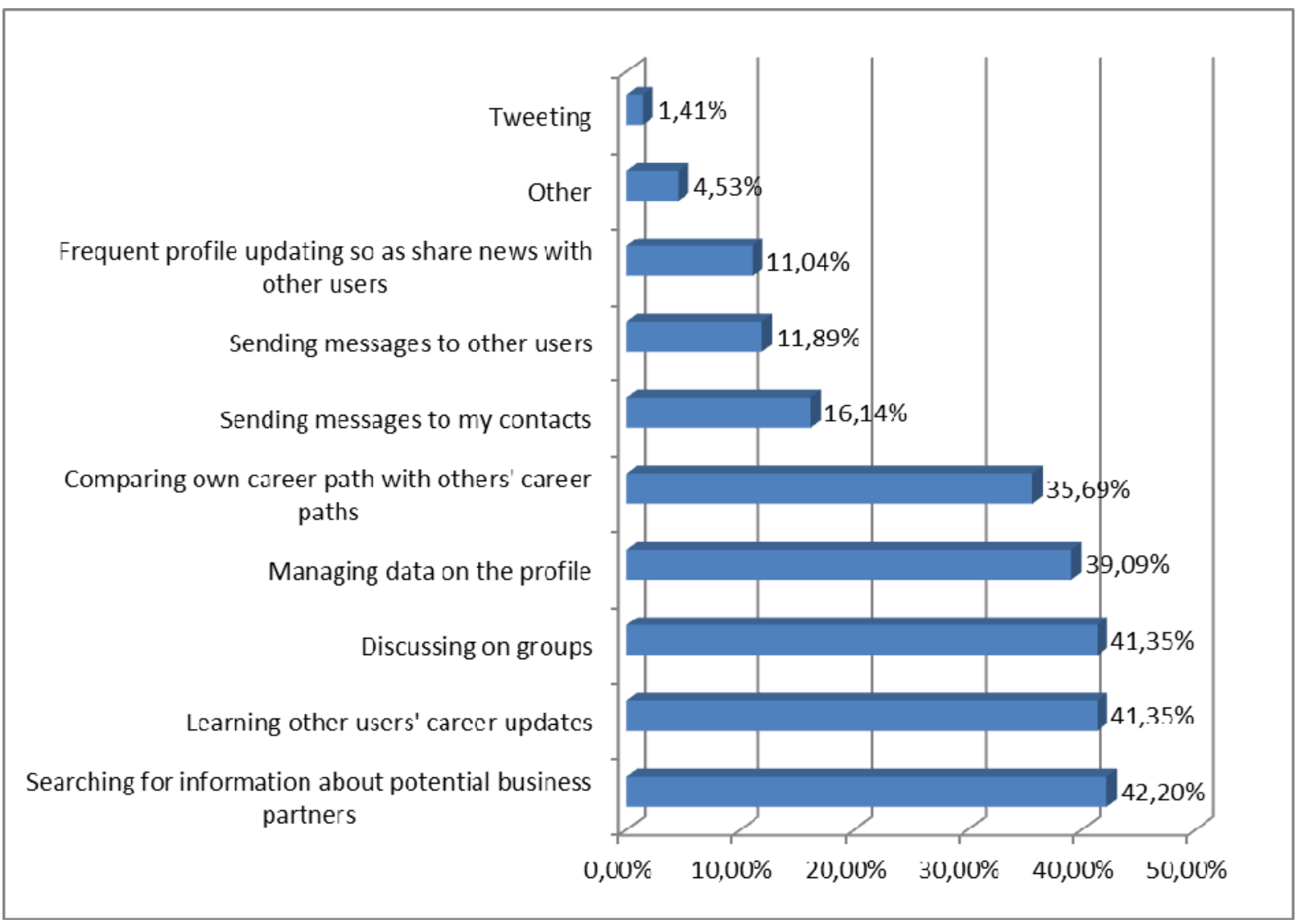

Graph 1. Activities of GoldenLine users from medical and pharmaceutical sector Source: research findings

The negative binomial regression analysis of the research, which was performed on GoldenLine among people with experience in the financial and banking sector as well as the medical and pharmaceutical industry, has shown that there are several factors which determine the number of job offers which are received by members of social networks:

- Experience in the given sector, a company of a specific size

The average number of job offers which was received by people with experience related to financial agency services and the pharmaceutical industry is almost twice as high when compared to employees in other sectors. Such correlation may be due to the fact that the financial agency services sector and the pharmaceutical sector have high demand for personnel and company recruiters and head-hunters more and more often search for employees by means of non-standard channels, including also social networks on social networking websites.

Both researches did not prove an existence of a correlation between the company size and the number of job offers. Theoretically, it might seem that these members of networks who have corporate experience will have majority over the others but it turned out that this correlation was not statistically significant.

- Experience on a position higher than assistant

The research involving people with experience in the financial and banking sector showed that the average number of job offers was approximately 4 times lower in case of users who worked as assistants as compared to higher level positions (Consultant, Expert, Manager, Supervisor, Director). In the research comprising people with experience in the medical and pharmaceutical industry, this number is over twice lower.

This could be explained by that, in case of searches for candidates for assistant 
positions, the traditional search methods (e.g. announcements) should be sufficient. In order to reach a candidate with a longer experience, it is worth using the online social networks.

- Duration of having an account on a social networking website

The obvious correlation is that the longer the users were registered on a social networking website, the more job offers they received since the moment of registration until the beginning of the research. This correlation is confirmed by the research carried out among people with experience in the financial and banking sector. Results gathered among people with experience in medical and pharmaceutical sector prove that the number of job offers received over the last year is higher among users with longer registration period at the GoldenLine.pl website. This may result from the fact that people who have been in a specific social network for a longer period of time have more contacts which can, in turn, generate more job offers.

- Relationships in a social network

Relationships (number of contacts, their characteristics) were analysed only in the research comprising people in the medical and pharmaceutical industry. The number of contacts has a positive influence on the number of the received job offers. Moreover, most offers which the network users receive come from head-hunters in recruitment agencies. Only $4,24 \%$ of survey respondents received offers from people with whom they had been in a direct contact. Certainly more contacts $(7,36 \%)$ were received by people who belonged to the second and third degree of contacts which indicates a relatively high importance of weak ties.

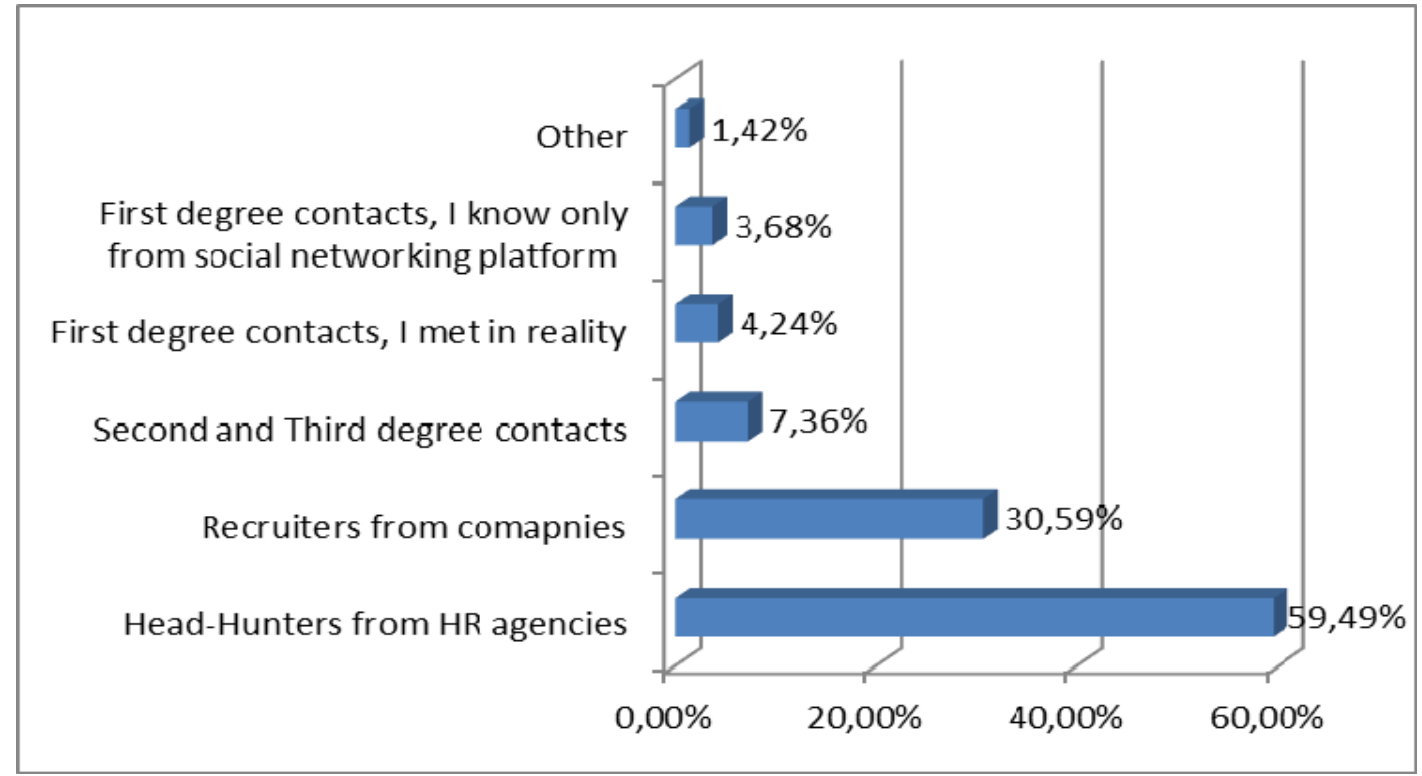

Graph 2. Characteristics of job offer senders (medical and pharmaceutical sector)

Source: research findings-users' goals on social networking platform

Network as covers view has its application especially, when we come across a longterm relationship between the employer and the employee and when the employee would like to avoid situation in which his employer finds out that the employee is looking for a new job. Almost $85 \%$ of the survey respondents from the medical and pharmaceutical industry confirm that one of the benefits of having an account at the GoldenLine.pl website is the opportunity of being available for recruiters and head-hunters as well as not giving the current employer reasons to believe that an active job search is being done (which is usually associated with sending application documents). 
The research also confirms that the online social networks are used to look for a job. Graphs 3 and 4 show that more than 3/4 survey respondents have pointed out that they had registered on the GoldenLine.pl website in order to receive job or cooperation offers. Expanding business contacts, access to information and new contacts are objectives of secondary importance.

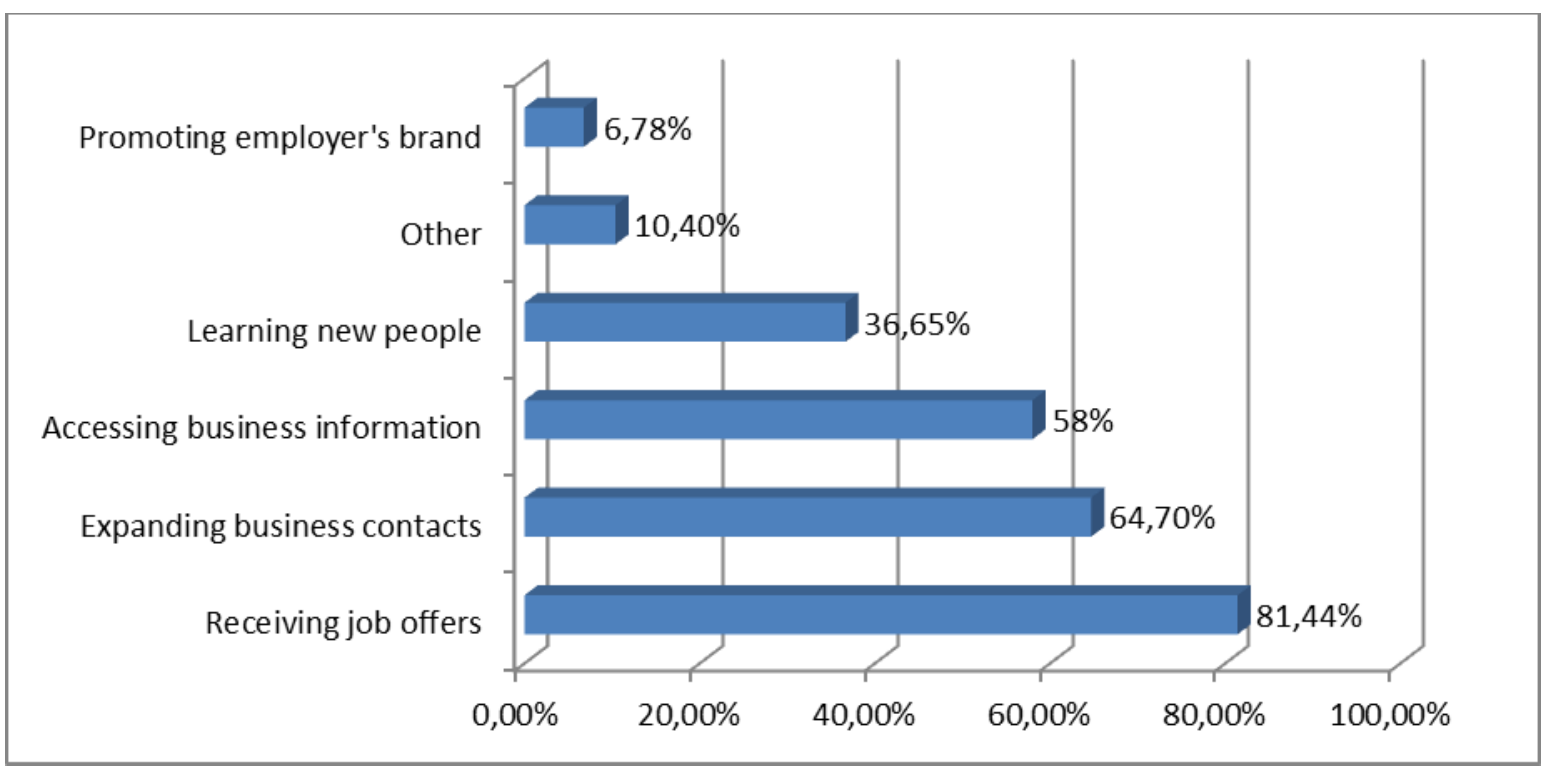

Graph 3. Registration goal on the social networking platform (finance and banking industry) Source: Research findings 


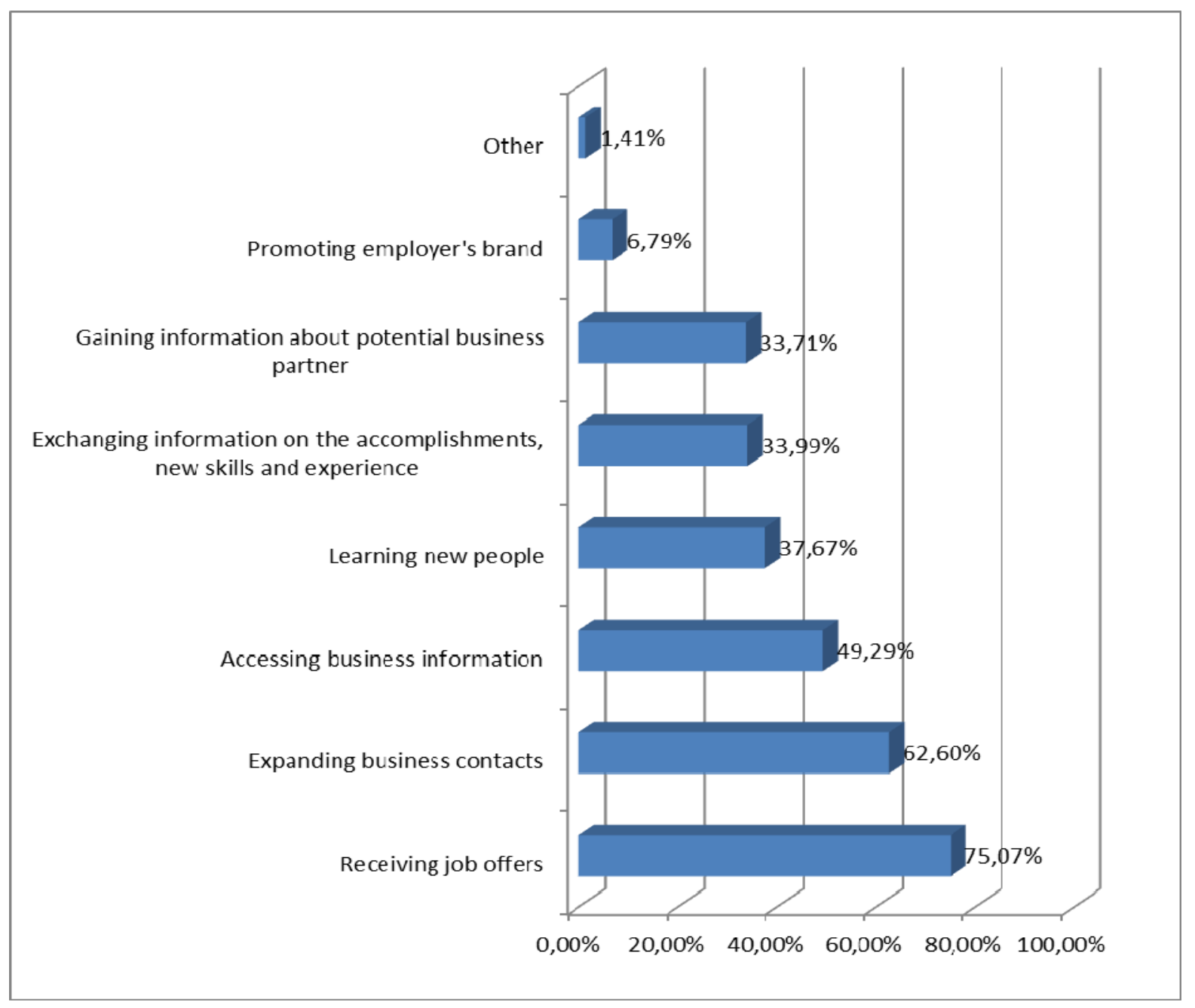

Graph 4. Registration goal on the social networking platform (medical and pharmaceutical industry)

Source: Research findings

\section{Individual social strategy and benchmarking}

Every user of a social network can develop a strategy in the network. Graph 1 presents activities which people with experience in the medical and pharmaceutical industry undertake on GoldenLine. The research demonstrated that people who determined the reception of job offers as the purpose of their registration more often undertook activities related to managing information on their own profiles, frequently updating the information for the purpose of sharing it with other users, comparing their own professional career path with the paths of others. A statistically significant correlation was also found between these activities which took place in various combinations and the number of received job offers. These activities may be recognized as a kind of social benchmarking which consists in using similar practices in a social network in relation to the network users who succeeded professionally and socially.

\section{Corporate social strategy}

The research shows that the knowledge of the superior and subordinates about having 
an account on GoldenLine concerns more than half of those surveyed users, who come from the financial and banking sector and about 30\% of respondents from the medical and pharmaceutical industry. Moreover, the responses of the survey respondents showed that the longer a user has been registered at a social networking website, the greater the probability is that the superior knows about it. This may be due to the fact that the social networking websites are sometimes topics of conversations at work or form objectives of relationships which the superior establishes in the social networks. Most conversations concern job offers, discussions on forums come second and trainings come third.

Another conclusion is that if the superior knows about one's having an account on GoldeLine, the frequency of logging in is greater.

The results of the I National Polish Survey of Employees "Internet at Work" [Polish: I Ogólnopolskie Badanie Pracowników "Internet w Pracy"] (PBI, 2010) show also that many people more and more often use the web at their place of work also for private purposes. The ways in which employers react to the private use of the Internet at work vary. Half of the employees replied that they had the superior's consent to the use of the web for private purposes; every fifth surveyed person replied that it was forbidden whereas almost every third person may use the Internet only in exceptional circumstances.

Employees expected the employer to include his policy regarding the use of the web for private purposes in the labour regulations. It turns out that in most companies where the surveyed persons worked there were no such regulations. Moreover, 20\% persons did not know whether there were such regulations in the company. Only 23\% persons declared that there was a document determining the accepted way of using the web at their workplace.

The research did not refer directly to the online social networks; however, due to the fact that presently the social networks are those which have an increasingly big influence on the operation of companies and personnel, the conclusions from the research may also be analysed in the context of the social media.

The social networks can be very useful for employers under condition that a social strategy has been developed in the company. The management very often limits itself to placing a few ads or publish a few announcements on a social networking website. However, these activities do not have much in common with a social strategy. Companies should be using a social network to give new opportunities to their members, especially such opportunities which are unreal or hardly available in course of everyday's operation (Silverthorne, 2009).

Graph 5 shows in what way companies use online social networks. Only 3,16\% of the survey respondents with experience in the banking and financial sector acknowledged that there was a social strategy in the company whereas as many as $58 \%$ of the survey respondents replied that the company did not use the online social networks. 
Social strategy, which attracts differents users, promotes employer's brand and provides advantages for both company and users

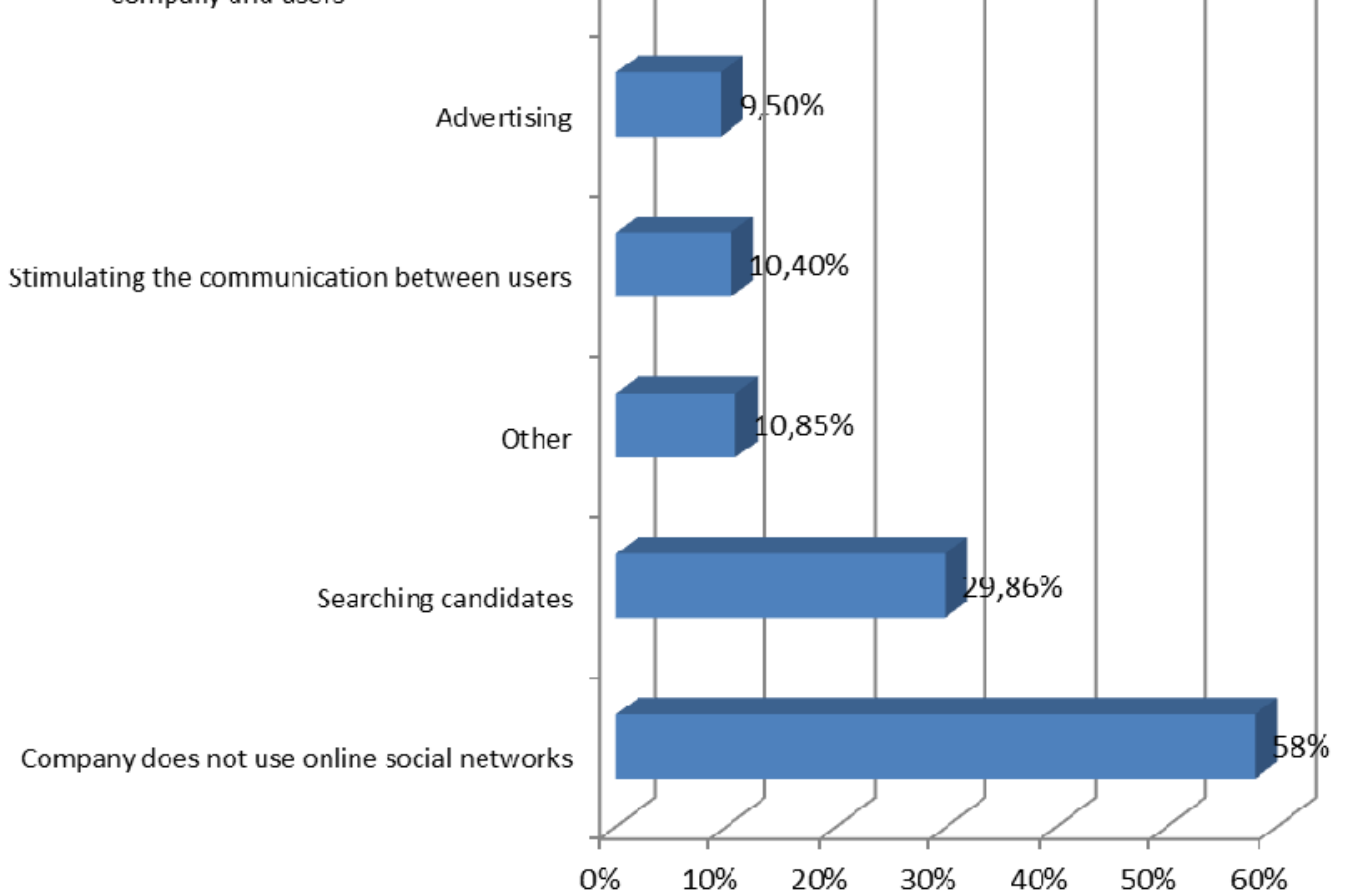

Graph 5. How companies use online social network (finance and banking sector) Sources: Research findings

In order to gain better outcomes, companies can use online social networks in different ways, like for example:

- Searching candidates (especially passive candidates who do not actively look for a job, but are open to participation in recruitment projects).

- Analysing the users' activities and encouraging them to employer branding activities.

- Stimulating communication among employees, knowledge sharing and group discussion.

\section{Summary}

The online social networks are a very important factor both for companies in terms of human resources and for individuals as far as their own career management is concerned.

It concludes from the analysis of the online social networks that users undertake highly diverse activities, such as e.g. searching for and reviewing information about business partners, getting acquainted with other users' professional careers, discussions on forums, management of information on their own profiles. It very often happens that these activities are accompanied by or undertaken to receive job offers.

Apart from the above mentioned activities which could be referred to as a kind of social benchmarking, the participants of the online social networks should take the following issues into account:

- experience in sectors which feature high level of the labour market dynamics; 
- experience on a position higher than assistant;

- duration of membership of a social networking website;

- contact with head-hunters who are the major source of job offers;

- development of a network of contacts (as the week ties usually provide more job offers than the strong ones).

The companies may also take advantage of the existence of social networks by developing an adequate social strategy which would make it possible to reach employees, create one's own image and stimulate communication among the users.

\section{References}

Arnison, L., \& Miller, P. (2002), Virtual teams: A virtue for the conventional team, Journal of Workplace Learning, 14(4), pp. 166-173.

Baum, J., and Oliver, C. (1992), Institutional Embeddedness and the Dynamics of Organizational Populations, American Sociological Review, 57 (4), pp. 540-59.

Burt, R.S. (1992), Structural Holes, Harvard University Press, Cambridge, MA, US.

Casciaro, T., and Piskorski M.J., (2005), Power Imbalance, Mutual Dependence, and Constraint Absorption: A Closer Look at Resource Dependence Theory, Administrative Science Quarterly, 50, pp. 167-199.

Dore, R.S. (1983), Goodwill and the Spirit of Market Capitalism, British Journal of Sociology 34, pp. 459-82.

Uzzi, B. (1996), The Sources and Consequences of Embeddedness for the Economic Performance of Organizations: The Network Effect, American Sociological Review 61, pp. 674-98.

Granovetter, M. (1974), Getting a job: A study of contacts and careers, Harvard University Press, Cambridge, MA, US.

Kotter, J. (1990), What Leaders Really Do, Harvard Business review, vol. 68, no. 3, p. 103.

Parr B., LinkedIn Surpasses 100 Million Users [INFOGRAPHIC], http://mashable.com/2011/03/22/linkedin-surpasses-100-million-users-infographic, (accessed 1 October 2011)

PBI (2010), Internet w pracy - wyniki I Ogólnopolskiego Badania Pracowników, http://www.pbi.org.pl/index.php/ida/2/?aktualnoscID=108\&p=1, (accessed 1 October 2011).

Pfeffer, J. and Salancik G.R. (1978), The External Control of Organizations: A Resource Dependence Perspective, Harper \& Row, New York.

Piskorski, M.J. (2008), Networks as covers: Evidence from an on-line social network, Working Paper, Harvard Business School.

Podolny, J. (1993), A Status-Based Model of Market Competition, American Journal of Sociology, 98, pp. 829-872.

Silverthorne, S. (2009), Understanding Users of the Social Networks, http://hbswk.hbs.edu/item/6156.html, (accessed 20 October 2011).

Zuckerman, E., Kim, T., Ukanwa, K, and von Rittmann J. (2003), Robust Identities or NonEntities? Typecasting in the Feature Film Labor Market, American Journal of Sociology, 108, pp. 1018-1075.

Zuckerman, E., (2004), Structural Incoherence and Stock Market Activity, American Sociological Review, 69, pp. 405-432. 